\title{
Flotation of silicates gangue from hematite containing products
}

\author{
I.V. Filippova, L.O. Filippov, V.V. Severov \\ Laboratoire Environnement et Minéralurgie, LEM CNRS-INPL, Nancy University, \\ Rue du Doyen M. Roubault, B.P.40, F-54501 Vandoeuvre-lès-Nancy, France \\ Moscow Institute Steel and Alloys, 4, Leninsky prospect, 119049 Moscow, Russia \\ inna.filippova@ensg.inpl-nancy.fr
}

This work presents the results on the application of reverse cationic flotation to obtain the hematite concentrates with weak silica content from the tailings of wet magnetic separation of magnetite. Fine particle size, complex mineralogy and presence of locked particles determine the impossibility of direct production of hematite concentrate by flotation or magnetic separation. The gravity concentration allows obtaining of iron concentrate from the wellprepared feed (size fraction $-53+20$ micron) but with very low recovery. Thus, the hematite concentrates with weak silica content and satisfactory iron recovery were obtained by reverse cationic flotation, when it was fed with iron pre-concentrate produced by high gradient magnetic separation. However, conducting the reverse cationic flotation implies a depression of hematite by starch and flotation of silicates by amine collectors. Simultaneously, the adsorption of starch occurred on the quartz particles covered by iron oxides and on minerals, which contain Fe (II), Fe (III) and Al-ions in their structure. Consequently, an efficient flotation of entire silicate complex is possible, if the collector used favours a destruction of the hydrated layer on the minerals, which are capable to fix the starch.

\section{Introduction}

At the Kursk Magnetic Anomaly deposits in Russia the bulk of iron ores is represented by poor, finely disseminated jaspilites with very complex mineral composition and tight intergrowth of ore and gangue minerals. The principal ore minerals are magnetite and hematite with traces of martite. In addition, the contained $\mathrm{Fe}$ is for the most part intercrystallized with gangue minerals: mica (celadonite), amphiboles (cummingtonite), pyroxenes (aegirine, omphacite) and carbonates (ankerite, Fe-dolomite, siderite). Existing technologies, namely the wet magnetic separation, allows the processing of magnetite quartzites only, while oxidized iron ores are refused. The annual losses of iron (hematite) with tails of wet magnetic separation in the processing of the concentrated magnetite quartzites is over 2.0 million tons just on a single production facility.

Thus, the goal of this work is to investigate possibilities for development of an effective and profitable technology, based on reverse cationic flotation, to obtain hematite concentrates with $\mathrm{Fe}$ content over $63 \%$ and $\mathrm{SiO}_{2}$ content less than $6 \%$ from tailings of wet magnetic separation with average Fe content $25 \%$ and average $\mathrm{SiO}_{2}$ content $54 \%$ in the process of concentrating of jaspilites at the Mikhailovsky iron ore mining and processing plant (MGOK).

\section{Methodology}

To develop and design a flow sheets for processing of refused iron ore tailing with hematite content at the MGOK, the research was conducted along the following three lines:

1. Production of a high-quality hematite concentrate from initial tailings by reverse cationic flotation.

2. Reverse cationic flotation with iron pre-concentrate produced by gravity separation (spiral separators).

3. Pre-concentration of iron ore minerals by high-gradient magnetic separation with subsequent reverse cationic flotation. 


\section{Results and discussion}

\subsection{Mineralogy of iron containing tailings}

Results of the particle size analysis of initial hematite tailings are presented in Table 1. From the data given in the table, it is seen that over $94 \%$ of Fe belongs to the size class $-0.053 \mathrm{~mm}$. As revealed by the XRD and SEM analysis (fig. 1), the main ore mineral is hematite, with less than $1 \%$ of magnetite in the total mineral mass. There also occurs siderite as released grains or in poor aggregates with quartz. There are a wide variety of gangue minerals, represented mostly by quartz $(\sim 45 \%$ of total minerals). It should be noted that a significant part of free quartz

Table 1. Grade and distribution by size for tailings sample

\begin{tabular}{|c|c|c|c|}
\hline $\begin{array}{c}\text { Size } \\
\text { range } \\
(\mu \mathrm{m})\end{array}$ & $\begin{array}{l}\text { Wt } \\
(\%)\end{array}$ & $\begin{array}{c}\text { Grade of } \\
\text { Fe }(\%)\end{array}$ & $\begin{array}{c}\text { Distribution } \\
\text { of } \mathrm{Fe}(\%)\end{array}$ \\
\hline+106 & 3.36 & \multirow{3}{*}{10.13} & \multirow{3}{*}{5.40} \\
\hline+88 & 1.71 & & \\
\hline+53 & 8.26 & & \\
\hline+44 & 7.11 & 22.80 & 6.48 \\
\hline+20 & 43.15 & 34.87 & 60.16 \\
\hline+10 & 14.74 & \multirow{2}{*}{19.20} & \multirow{2}{*}{27.96} \\
\hline-10 & 21.67 & & \\
\hline Calc feed & 100.0 & 25.01 & 100.0 \\
\hline
\end{tabular}
grains, with grain size up to $0.25 \mathrm{~mm}$, is represented by structures with micro inclusions of magnetite $(<5 \mu \mathrm{m})$. Many quartz particles coated with iron oxides. Also, there are large amounts of mica - celadonite ( $11.5 \%$ of total minerals) as released grains of prismatic form

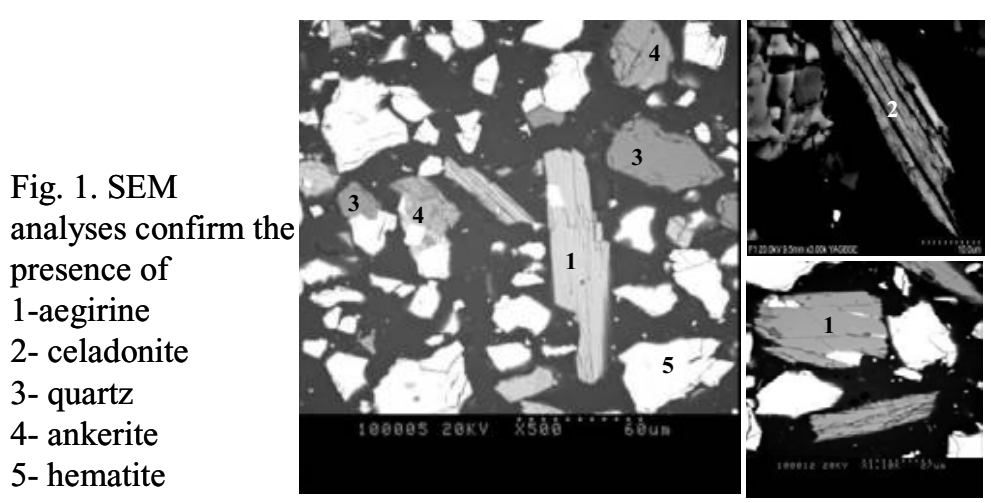
with sizes up to $0.05 \times 0.5 \mathrm{~mm}$, double or triple aggregations with quartz and hematite. FeMg-carbonates are represented by ankerite $(5.8$ $\%$ and Fe-containing dolomite (1\%), which mostly occur in complex aggregations with hematite and quartz. There is a substantial amount of amphiboles - cummingtonite $(2.3 \%)$ and pyroxenes - aegirine $(1 \%)$ and omphacite $(0.2 \%)$, which also occur mostly in aggregations with hematite. The extent of release of the minerals is between 60 and $80 \%$, still over half of released hematite grains belong to the fraction -0.01 $\mathrm{mm}$. The mineralogy analysis has shown that the main mineral samples of initial tailings have similar magnetic properties. Many quartz particles have micro inclusions of magnetite and are covered by iron oxide layer. This explains the fact that specific magnetism of the weak fractions of such quartz is even stronger than that of hematite. The presence of Fe ions in the crystalline structure of the silicates and carbonates determines their paramagnetic properties comparable to those of hematite. These factors definitely explain the passing of these silicates and carbonates into magnetic concentrate. Although hematite density $\left(5.2 \mathrm{~g} / \mathrm{cm}^{3}\right)$ is much higher that that of the minerals of this silicate complex (average value $3.0 \mathrm{~g} / \mathrm{cm}^{3}$ ), large amounts of hematite locked with silicates gangue and silicate-carbonate aggregates decrease gradations scale of density difference, complicating an effective gravity separation.

Therefore, an effective concentration of tailings with such complex mineral composition requires application of pre-concentration methods based on different physical properties, while particles that have similar physical properties should be separated using their physicochemical properties at the same gradation scale.

Flotation tests with various size fractions of amphiboles and quartz show the efficiency of the amine collector mixtures and of the collector formulations based on the amines and nonionic reagents. 


\subsection{Flotation of the tailings sample}

Research was carried out on initial hematite tailings with removed $+0.053 \mathrm{~mm}$ fraction and de-slime at $20 \mu \mathrm{m}$. A thorough quartz removal was achieved $\left(4.9 \% \mathrm{SiO}_{2}\right.$ in the obtained concentrate) due to alkyletheramine used as collector, rated at $140 \mathrm{~g} / \mathrm{t}$ total, but Fe content was below $60 \%$ which indicates the presence of significant amount of iron carbonates and silicates with low silica content (celadonite, aegirine). The presence of these minerals in the obtained concentrate can be explained by poor floatability of carbonates by cationic collectors, while iron silicates, especially when locked with Fe oxide, are depressed by starch and are poorly passed into froth pulp ${ }^{1,2}$. To improve technological parameters, the $+0.044 \mathrm{~mm}$ fraction was removed from the obtained concentrate. Concentrate output was less than $7 \%$ of initial tailings.

\subsection{Flotation of the gravity pre-concentrate}

Research was carried out on gravity pre-concentrate with $\mathrm{Fe}$ content $63 \%$ and $\mathrm{SiO}_{2}$ content $7 \%$. Thus the goal of the flotation research was to develop and test flotation routines that would remove the silicate complex with the lowest losses of iron. Examination of the mineralogical makeup of the gravity concentrate has shown that the concentrate was impoverished primarily by rich double and complex aggregates of hematite with gangue minerals as well as by released grains of monometrical ankerite with size fraction 30-35 $\mu \mathrm{m}$. There were occasional free grains of prismatic celadonite with average size $10 \times 100 \mu \mathrm{m}$.

Flotation results show that the use of collector based on a mixture of alkyletherdiamine, alkyletheramine and fatty alcohols of isomeric structure (isotridecanol) with concentration at $140 \mathrm{~g} / \mathrm{t}$ made it possible to almost completely remove celadonite grains of the size fraction 80-100 $\mu \mathrm{m}$ and aggregations (mostly weak) of hematite with gangue minerals reaching a high level of flotation selectivity. There remained in the concentrate rich aggregations of hematite with quartz, which are removed at increased collector rates, as well as iron carbonates. The obtained concentrate had $65.1 \% \mathrm{Fe}$ and $5.2 \% \mathrm{SiO}_{2}$, with $\mathrm{Fe}$ recovery $94 \%$ upon flotation and less than $7 \%$ output of initial tailings.

\subsection{Flotation of the magnetic pre-concentrate}

From the product with $25 \% \mathrm{Fe}$ content and $54 \% \mathrm{SiO}_{2}$ content, magnetic pre-concentrate was obtained with $44 \% \mathrm{Fe}$ content and $27 \%$ of $\mathrm{SiO}_{2}$ with a $37-\%$ output of initial tailings. Research of magnetic pre-concentrate has shown that $80 \%$ of Fe belongs to the $-0.053 \mathrm{~mm}$ size fraction, and this fraction is dominated by released ore grains; among gangue grains it contains quartz as irregular and isometric grains, together with celadonite and aegirine as lathlike and prismatic grains. Therefore, prior to flotation, the $+0.053 \mathrm{~mm}$ size fraction was removed and de-

slime at $20 \mu \mathrm{m}$ was carried out.

The effect of different cationic collectors (based on amines) and starch concentration on the quality of hematite concentrates was studied.

Electrokinetic's investigations (fig. 2) confirm the

Fig.2. Effect of mixed amine on magnesiohornblende (amphibole) zeta-potential.

Electrokinetic's investigations confirm the enhanced adsorption of collector mixtures and of the collector formulations based on the amines and nonionic reagents on the hydrophilic mineral surfaces.

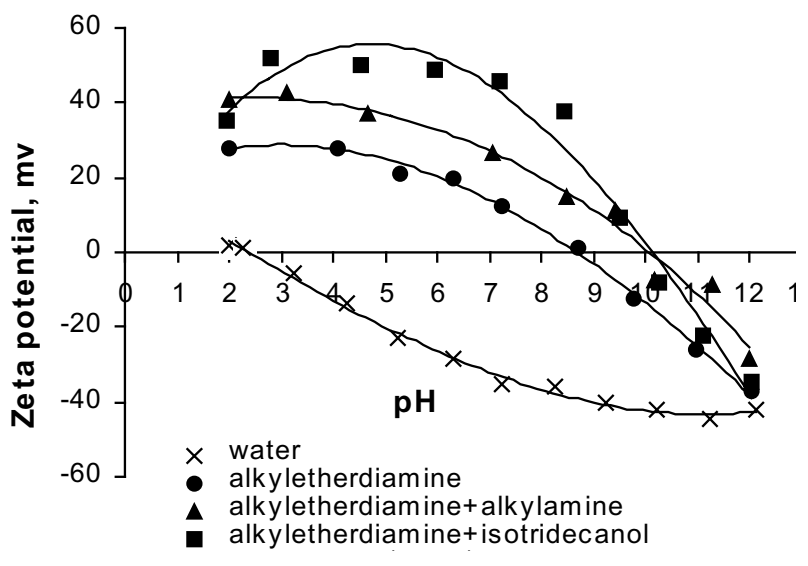


enhanced adsorption of collector mixtures on the hydrophilic mineral surfaces and the increased selectivity between hematite and ferromagnesian silicates. Application of a mixture of alkyletherdiamine and primary monoamine at 2:1 ratio with reagent dosage at $110 \mathrm{~g} / \mathrm{t}$ allowed formation of a stable adsorption layer on the quartz surface and on the nonhomogeneous surface of Fe-silicates, and ensured their rather complete flotation. Released quartz grains and weak aggregates of hematite with quartz were removed completely into the froth pulp, which is most probably explained by a stable attachment of primary monoamine on the quartz surface with formation of a monolayer by two-dimensional condensation $^{3}$. An optimal

Table 2. Hematite concentrates obtained from tailings samples by various separation techniques

\begin{tabular}{|c|c|c|c|}
\hline \multirow[b]{2}{*}{ Beneficiation method } & \multirow{2}{*}{$\begin{array}{l}\text { Weight }(\%) \\
\text { output from } \\
\text { initial tailings }\end{array}$} & \multicolumn{2}{|c|}{ Grade $(\%)$} \\
\hline & & $\mathrm{Fe}$ & $\mathrm{SiO}_{2}$ \\
\hline Reverse flotation & 6.9 & 59.2 & 4.9 \\
\hline $\begin{array}{l}\text { Gravity concentration } \\
\text { Reverse flotation }\end{array}$ & 6.3 & 65.1 & 5.2 \\
\hline $\begin{array}{l}\text { High Gradient } \\
\text { Magnetic Separation } \\
\text { Reverse flotation }\end{array}$ & 11.3 & 63.3 & 5.9 \\
\hline
\end{tabular}

starch concentration during flotation of magnetic pre-concentrate by collector mixture is established to be within 250-600 g/t range. To increase technological parameters, the +0.044 $\mathrm{mm}$ fraction was removed from the obtained concentrate. The obtained hematite concentrate (table 2) fulfilled all target requirements, with Fe content $63.3 \%, \mathrm{SiO}_{2}$ content $5.85 \%$ and output of initial tailings at $11 \%$.

\section{Conclusions}

Research was carried out on tailings from wet magnetic separation during iron ores concentration at the Mikhailovsky iron ore mining and processing plant (Kursk region, Russia). This material has a very complex particle size distribution and mineral composition with total $\mathrm{Fe}$ content $25 \%$ and $\mathrm{SiO}_{2}$ content $54 \%$. Besides, a significant amount of iron is intercrystallized with silicate and carbonates.

Studied sample minerals are characterized by similar physical and physicochemical properties. Large amount of aggregates of hematite with gangue minerals would impoverish concentrate or increase removal of iron into concentration tailings. Therefore an effective concentration of this product necessitates application of combined technology based on reverse cationic flotation with pre-concentration of commercial mineral (hematite) by a physical concentration (gravity separation or high-gradient magnetic separation).

Laboratory research has shown that a collector based on a mixture of alkyletherdiamines with primary monoamine used in flotation of the silicate complex allows a target-grade concentrate, with $\mathrm{Fe}$ content over $63 \%$ and $\mathrm{SiO}_{2}$ less than $6 \%$. Application only of combined technology, HGMS-reverse flotation, ensured the target commercial property: an over 10-\% output from initial tailings.

1. A. E. C. Peres and M. I. Correa, Depression of iron oxides with corn starches, Minerals Engineering, 9(12), 1227-1234 pp (1996).

2. I. Dogu and A. I. Arol, Separation of dark-colored minerals from feldspar by selective flocculation using starch, Powder Technology, 139, 258-263 pp (2004).

3. Cases, J M, Physico-chemical phenomena in interface. Applications in the technique of flotation, Mémoires des sciences de la Terre, 13 (1968). 